\title{
Comparative analysis of maternal and grand-maternal photoperiodic responses of Trichogramma species (Hymenoptera: Trichogrammatidae)
}

\author{
Natalia D. VOINOViCH, Nina P. VAGHinA and Sergey Ya. REZNIK* \\ Zoological Institute, Russian Academy of Sciences, 199034 St. Petersburg, Russia; e-mails: nataliavoinovitch@hotmail.com; \\ nina@zin.ru; reznik1952@mail.ru
}

Key words. Hymenoptera, Trichogrammatidae, Trichogramma, diapause, photoperiod, temperature, maternal effect, grand-maternal effect, cumulative photoperiodic effect

\begin{abstract}
Maternal and grand-maternal photoperiodic responses of Trichogramma buesi, T. embryophagum, T. evanescens, T. piceum, T. principium, and T. telengai were investigated in laboratory conditions. During the experiment, grand-maternal and maternal generations developed at $20^{\circ} \mathrm{C}$ and one of the 4 photoperiodic regimes: $\mathrm{L}: \mathrm{D}=12: 12,14: 10,16: 8$, and $18: 6$ (in total, 16 combinations) while the progeny developed at $\mathrm{L}: \mathrm{D}=12: 12$ and one of the 3 thermal regimes: 13,14 , and $15^{\circ} \mathrm{C}$. The proportion of diapausing individuals in the progeny of all the studied species was significantly dependent on the direct influence of temperature and on the maternal photoperiodic response. The influence of the photoperiodic conditions during development of the grandmaternal generation was statistically significant in 5 of the 6 studied species, being relatively weak in $T$. embryophagum and $T$. telengai, whose geographical ranges extend up to north-western regions of Europe (possibly, these wasps enter diapause so early that the grand-mothers of the diapausing generation develop under long day conditions). Comparative analysis showed that the thresholds of the maternal and grand-maternal photoperiodic responses coincided or almost coincided. The grand-maternal effect was stronger in the progeny of maternal females which developed under short day conditions than in those that developed under long day conditions. This pattern of interaction probably synchronizes the life cycle with seasonal changes because diapause is induced under decreasing day length and thus mothers of diapausing individuals develop at shorter daylength than do grand-mothers. We conclude that the grand-maternal and the maternal effects on Trichogramma progeny diapause are based on one and the same photoperiodic response. In nature, the grand-maternal effect increases the proportion of diapausing individuals in the progeny of females which have developed under short day conditions during two generations, thus achieving a "cumulative" photoperiodic effect.
\end{abstract}

\section{INTRODUCTION}

Photoperiod and temperature are well known to be the most common factors inducing winter diapause in temperate zone insect species. These environmental tokens are perceived by the sensitive stage of development which usually precedes the diapausing stage (Tauber et al., 1986; Zaslavski, 1988; Saunders et al., 2002; Danks, 2007; Saunders, 2010). However, the so called "maternal effect" is observed in a number of insect species: the proportion of diapausing individuals depends on the factors that have influenced females of the maternal generation. Moreover, in certain insect species, the tendency to diapause depends on the conditions of development of females of two or even several preceding generations (Lees, 1960; Bogdanova et al., 1978; Zaslavski \& Umarova, 1981; Mai Phu Qui \& Zaslavski, 1983; Vinogradova, 1991; Reznik \& Kats, 2004; Saunders, 2010; Reznik et al., 2012a). While the physiological mechanism and the ecological significance of the maternal influence on the diapause induction have been thoroughly studied in several insect species (Zaslavski, 1978, 1988; Tauber et al., 1986; Mousseau \& Dingle, 1991; Mousseau \& Fox, 1998; Denlinger, 1998, 2002; Saunders et al., 2002; Danks, 2007), the grand-maternal photoperiodic response has not been sufficiently investigated. In particular, one important question remains: are maternal and grandmaternal effects (if both are present in an insect species) nothing more than different manifestations of the same photoperiodic response or they are based on different and, to some extent, independent reactions? The main aim of the present work was to address this question.

The subjects of our study, minute egg parasitoids in the genus Trichogramma are widely used not only for biological control of lepidopteran pests (Smith, 1996) but also as insect models for various eco-physiological studies. In nature, Trichogramma species of the temperate zone overwinter as diapausing prepupae. Low temperature is the most important environmental cue that influences Trichogramma embryos and larvae inducing the prepupal diapause. In addition, under near-threshold temperatures $\left(12-15^{\circ} \mathrm{C}\right)$ the proportion of diapausing individuals usually depends on the photoperiodic conditions during the development of the maternal females (Zaslavski \& Umarova, 1981, 1990; Boivin, 1994; Laing \& Corrigan, 1995; Reznik et al., 2011a, b). Moreover, in some Trichogramma species, a grand-maternal effect has also been observed (Zaslavski \& Umarova, 1981; Mai Phu Qui \& Zaslavski, 1983; Reznik \& Kats, 2004). Both maternal and grand-maternal effects on Trichogramma diapause induction are based on long-day photoperiodic response: the proportion of diapausing progeny increases

\footnotetext{
* Corresponding author.
} 
TABLE 1. Natural geographic ranges of the studied Trichogramma species and origin of the studied strains.

\begin{tabular}{lll}
\hline Trichogramma species & Natural geographic range of the species * & Origin of the studied strain \\
\hline T. buesi & Southern Europe, Southern Russia, Central Asia & Saratov prov. (Russia) \\
T. embryophagum & Europe, European Russia, Kazakhstan & Voronezh prov. (Russia) \\
T. evanescens & Europe, Central and Southern Russia, Southern Siberia, Kazakhstan & Volgograd prov. (Russia) \\
T. piceum & Southern Europe & Bulgaria \\
T. principium & Southern Europe, Central Asia & Chimkent prov. (Kazakhstan) \\
T. telengai & Europe, European Russia, Siberia & Moscow prov. (Russia) \\
\hline
\end{tabular}

* Data from (Sorokina, 2001) and from the database "Fauna Europea" (http://www.faunaeur.org).

with decreasing daylength. This interaction of maternal and grand-maternal photoperiodic effects and direct thermal responses inhibits diapause induction during spring and early summer, when the daylength is much longer than at the same average temperature during late summer and autumn.

Returning to the main aim of our study, we can advance two working hypotheses.

(1) If the grand-maternal and maternal photoperiodic responses are relatively independent physiological reactions, the threshold day length of the grand-maternal photoperiodic response would be longer than that of the maternal response. This relationship is expected because grand-mothers of diapausing individuals experience longer daylength than do mothers.

(2) For the same reason, we can expect that the grandmaternal photoperiodic response would be stronger (all other conditions being the same) when maternal females develop under the shorter daylengths than grand-maternal females do (or, more generally, the grand-maternal effect would be stronger in the progeny of maternal females developed under the short day conditions).

We have tested these hypotheses using six Trichogramma species. In 3 of them (Trichogramma buesi Voegele, $T$. evanescens Westw., and T. principium Sug. et Sor.) the grand-maternal photoperiodic response was shown to occur (Zaslavski \& Umarova, 1981; Mai Phu Qui \& Zaslavski, 1983; Reznik \& Kats, 2004), while $T$. telengai Sor., T. embryophagum Htg., and T. piceum Djur. have not been investigated in this respect. Thus, a secondary aim of our investigation was to evaluate the occurrence of the grand-maternal photoperiodic response among Trichogramma species.

\section{MATERIAL AND METHODS}

The study was conducted with laboratory strains of 6 Trichogramma species (Table 1). In the laboratory these strains were cultivated on eggs of the Angoumois grain moth, Sitotroga cerealella Oliv. (Lepidoptera: Gelechiidae) during 20-300 generations at temperatures of $20-25^{\circ} \mathrm{C}$ and day length of $18-20 \mathrm{~h}$, i.e., under the conditions which averted diapause. Immediately before the study, the strains were reared under more strictly controlled diapause averting conditions $\left(20^{\circ} \mathrm{C}, 18 \mathrm{~L}: 6 \mathrm{D}\right.$, and $75 \%$ $\mathrm{RH})$ for at least 10 generations. For each experiment, a paper card with 3000-4000 grain moth eggs glued with polyvinyl acetate suspension were subjected for $2 \mathrm{~h}$ to parasitization by ca 1000 females of the laboratory line. Then this card with parasitized host eggs (the grand-maternal generation) was separated into 4 parts which were randomly placed in 4 test tubes incubated at $20^{\circ} \mathrm{C}$ and $75 \% \mathrm{RH}$ under 4 photoperiodic regimes: $\mathrm{L}$ :
$\mathrm{D}=12: 12,14: 10,16: 8$, and $18: 6$. At the day of the mass emergence of the grand-maternal generation, a new paper card with 3000-4000 fresh eggs of the grain moth was placed in each tube and subjected to parasitization for $2 \mathrm{~h}$. Then these cards (the maternal generation) were also separated into 4 parts and randomly distributed among the same 4 photoperiodic regimes. Finally, at the day of the mass emergence of the maternal generation, a new paper card with 3000-4000 fresh eggs of the grain moth was placed in each tube, subjected to parasitization for $2 \mathrm{~h}$, and separated into 18 small cards (progeny generation) which were randomly distributed among 3 temperature regimes: 13,14 , and $15^{\circ} \mathrm{C}$ at $12 \mathrm{~L}: 12 \mathrm{D}$ and $75 \% \mathrm{RH}$. The above temperature regimens were chosen because they are close to the threshold of diapause induction for all the species under study, as suggested by earlier investigations (Zaslavski \& Umarova, 1981, Sorokina \& Maslennikova, 1986; Zaslavski \& Umarova, 1990; Reznik et al., 2002; Reznik \& Kats, 2004; Reznik, 2011; Reznik et al., 2011a, b) and by our (unpubl.) pilot data. Thus, each experiment included 48 treatments, i.e. combinations of 4 "grand-maternal photoperiods" (photoperiodic conditions of development of the grand-maternal generation) with 4 "maternal photoperiods" (photoperiodic conditions of development of the maternal generation) and with 3 thermal regimes of development of the progeny. It is known that in Trichogramma the tendency to diapause may vary over generations of a laboratory line even under stable environmental conditions (Zaslavski \& Umarova, 1981, 1990; Reznik et al., 2002). Thus, for each Trichogramma species, 4 experiments were conducted using different (sequential) generations of laboratory strains. To ensure uniformity, parasitization was always conducted at the same time of the day (between 4 and $6 \mathrm{~h}$ after the light-on).

In 10 days after the mass emergence of the non-diapausing fraction of the progeny generation all parasitized host eggs were dissected, diapausing prepupae (each living prepupa was assumed to be diapausing) and non-diapausing individuals (mostly emerged adults, few dead adults inside the host chorion, and sporadic pupae) were recorded. As Trichogramma females usually lay only one egg in each egg of the grain moth, the number of emerged adults was estimated by the number of parasitized eggs with emergence holes. The few (less than 1-2\%) individuals that died during the larval or prepupal stages were excluded from consideration. Then the percentage of diapausing individuals was separately calculated for each small card of the progeny generation (50-100 host eggs parasitized during $2 \mathrm{~h}$ by a random sample from about 500 females) that was considered as a replication for the statistical treatment. Thus, the experiment included 6 replicates for each of the 48 experimental treatments conducted with each of the 4 generations of each of the 6 Trichogramma species (a total of 6912 cards with more than 400,000 parasitized host eggs).

Medians and quartiles of untransformed data (percentages) were used as descriptive statistics. For further statistical treatment, proportions of diapausing individuals were arcsine square root transformed and analysed with ANOVA. It is known 

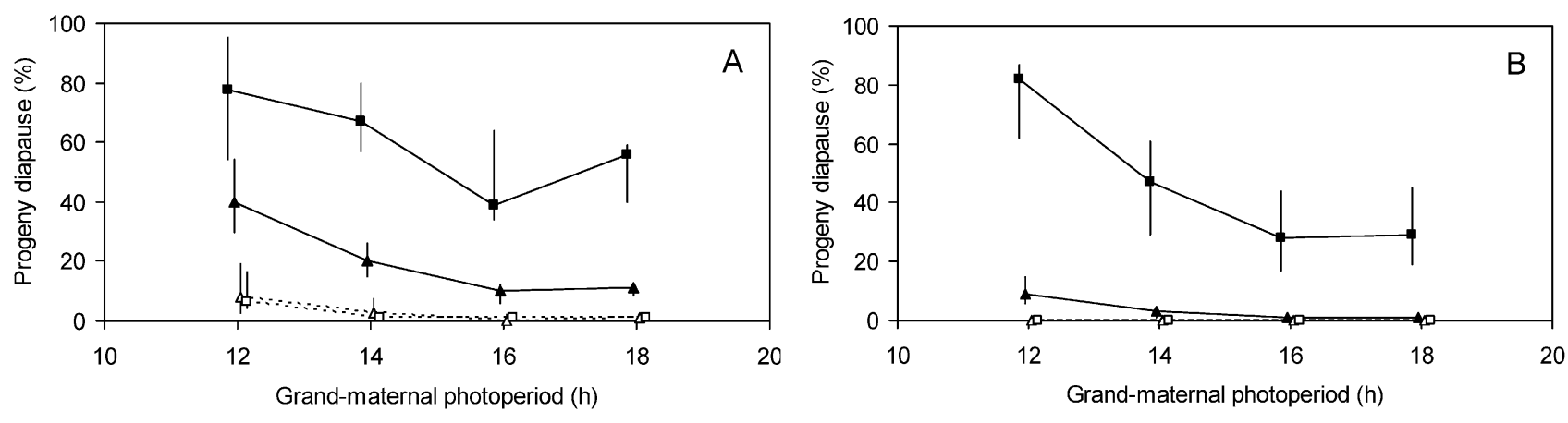

Maternal photoperiod $(\mathrm{h}): \longrightarrow-12 \longrightarrow 14 \cdots \Delta \cdots 16 \cdots \cdots 18$

Maternal photoperiod $(\mathrm{h}): \longrightarrow-12 \longrightarrow-14 \cdots \Delta \cdots 16 \cdots-18$
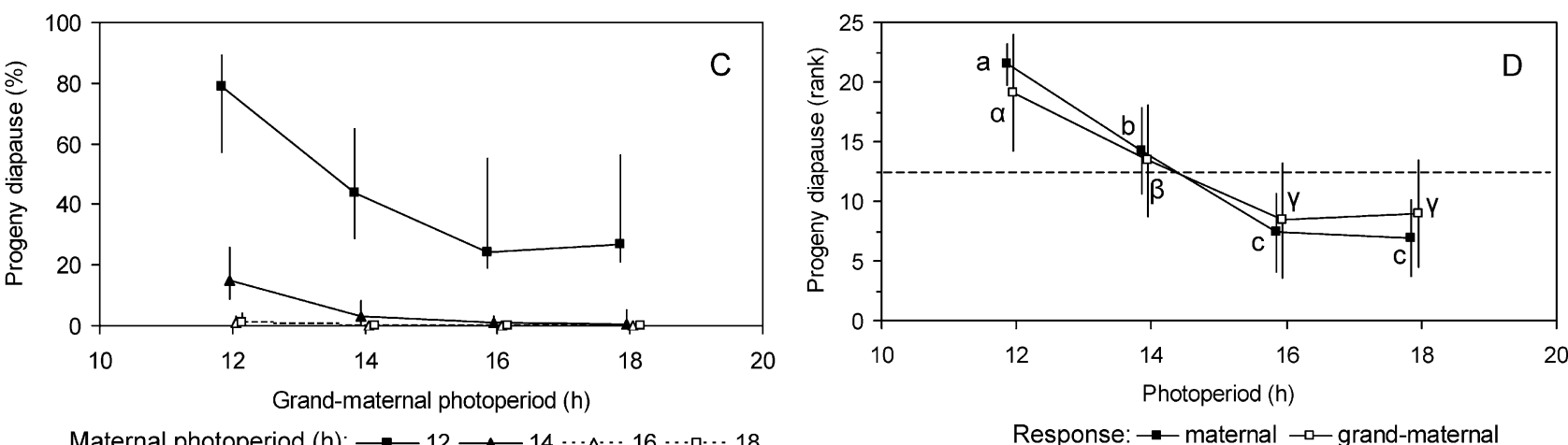

Maternal photoperiod $(\mathrm{h}): \longrightarrow-12 \longrightarrow 14 \cdots \Delta \cdots 16 \cdots \square \cdot 18$

Fig. 1. Maternal and grand-maternal photoperiodic responses of Trichogramma buesi at different thermal regimes of the progeny development. $\mathrm{A}, \mathrm{B}$, and $\mathrm{C}-$ the progeny developed at 13,14 , and $15^{\circ} \mathrm{C}$, respectively, medians and quartiles are shown. $\mathrm{D}-$ the pooled ranked data for all temperatures, means and SD are shown, means indicated by different Latin (for the maternal response) or Greek (for the grand-maternal response) letters are significantly different ( $p<0.05$ with the Tukey HSD test).

(see Introduction for the references) that maternal and grandmaternal photoperiodic responses in Trichogramma wasps can be revealed only when the progeny develop under temperatures close to the threshold of the diapause induction and the proportion of diapausing progeny strongly depends on temperature. However, it has been recently demonstrated (Reznik et al., $2012 \mathrm{~b}$ ) that although the impact of the maternal photoperiodic response can be revealed only within a very narrow thermal range, the relative strength of the diapause-inducing effect of different day lengths is independent of the temperature regimen of the progeny development. Thus, to reveal the general speciesspecific patterns of the maternal and the grand-maternal photoperiodic responses, the data were ranked in two ways. First, the proportions of diapausing progeny induced by different grandmaternal photoperiods (i.e. photoperiodic conditions of the developing grand-maternal generation) were separately ranked for each combination "temperature * maternal photoperiod * Trichogramma species" and then the ranks were pooled for each species and plotted against grand-maternal photoperiods. Second, the proportions of diapausing progeny induced by different maternal photoperiods (i.e. photoperiodic conditions of the developing maternal generation) were separately ranked for each combination "temperature * grand-maternal photoperiod * Trichogramma species" and then the ranks were pooled separately for each species and plotted against maternal photoperiods. These pooled ranked data for each species were analysed with one-way ANOVA and the Tukey HSD test. All the calculations were made with SYSTAT.

\section{RESULTS}

As seen in Table 2, the proportion of diapausing individuals was strongly dependent on the sum of the experi-

TABLE 2. Relative strength of the influence of temperature, grand-maternal photoperiod, maternal photoperiod, and difference between generations on the proportion of diapausing progeny of Trichogramma species (multiple correlation coefficient $\mathrm{R}, \mathrm{F}-$ ratios, and their significance calculated by 4-way ANOVA of arcsine-transformed data: *** $-\mathrm{p}<0.001, * *-\mathrm{p}<0.01, *-\mathrm{p}<0.05$, n.s. - not significant).

\begin{tabular}{|c|c|c|c|c|c|c|c|c|c|c|}
\hline \multirow{3}{*}{$\begin{array}{l}\text { Trichogramma } \\
\text { species } \\
\text { T. buesi }\end{array}$} & \multirow{2}{*}{\multicolumn{2}{|c|}{ Multiple R }} & \multicolumn{8}{|c|}{ F-ratios } \\
\hline & & & \multicolumn{2}{|c|}{ Temperature } & \multicolumn{2}{|c|}{$\begin{array}{c}\text { Grand-maternal } \\
\text { photoperiod }\end{array}$} & \multicolumn{2}{|c|}{$\begin{array}{c}\text { Maternal } \\
\text { photoperiod }\end{array}$} & \multicolumn{2}{|c|}{ Generation } \\
\hline & 0.985 & $* * *$ & 766.4 & $* * *$ & 765.0 & $* * *$ & 7779.2 & $* * *$ & 233.6 & $* * *$ \\
\hline T. embryophagum & 0.883 & $* * *$ & 624.2 & $* * *$ & 1.8 & n.s. & 209.2 & $* * *$ & 318.1 & $* * *$ \\
\hline T. evanescens & 0.977 & $* * *$ & 6352.9 & $* * *$ & 57.7 & $* * *$ & 1360.1 & $* * *$ & 145.1 & $* * *$ \\
\hline T. piceum & 0.960 & $* * *$ & 3019.7 & $* * *$ & 23.1 & $* * *$ & 827.4 & $* * *$ & 413.1 & $* * *$ \\
\hline T. principium & 0.985 & $* * *$ & 1633.9 & $* * *$ & 377.7 & $* * *$ & 7335.0 & $* * *$ & 164.8 & $* * *$ \\
\hline T. telengai & 0.957 & $* * *$ & 1596.5 & $* * *$ & 3.8 & $* *$ & 1943.4 & $* * *$ & 75.0 & $* * *$ \\
\hline
\end{tabular}



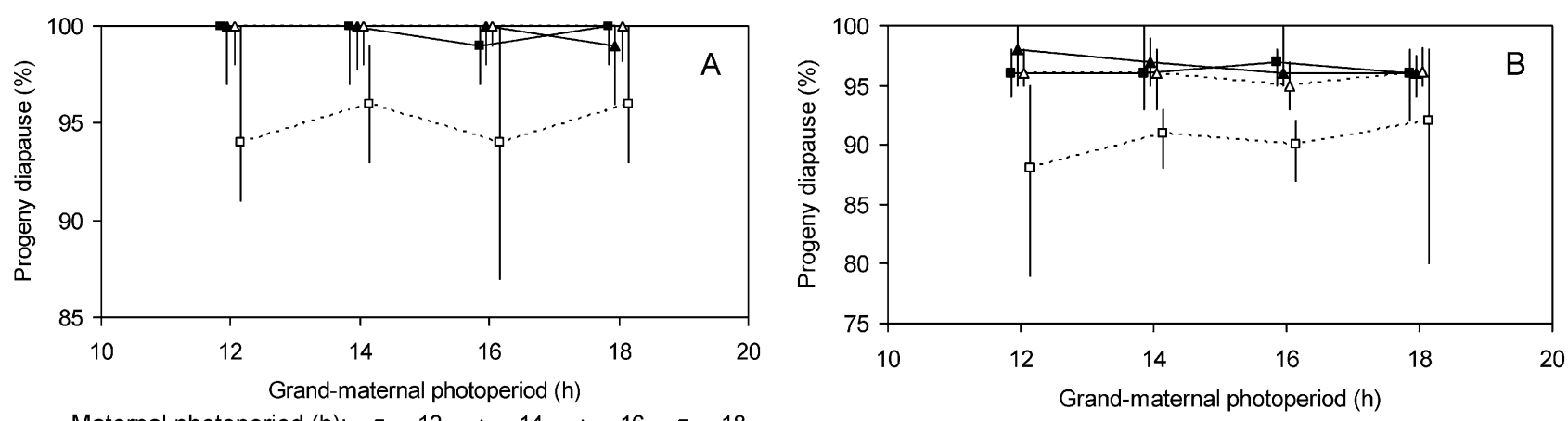

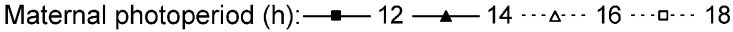

Maternal photoperiod $(\mathrm{h}): \longrightarrow-12 \longrightarrow 14 \cdots \Delta \cdots 16 \cdots \square \cdots 18$
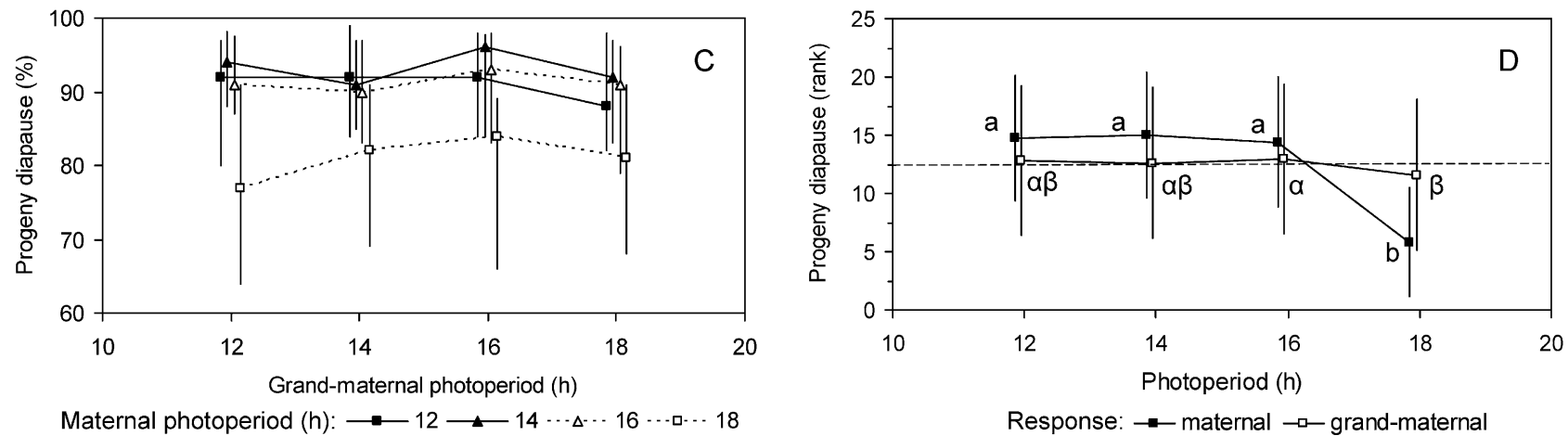

Fig. 2. Maternal and grand-maternal photoperiodic responses of Trichogramma embryophagum at different thermal regimes of the progeny development. $\mathrm{A}, \mathrm{B}$, and $\mathrm{C}-$ the progeny developed at 13,14 , and $15^{\circ} \mathrm{C}$, respectively, medians and quartiles are shown. $\mathrm{D}-$ the pooled ranked data for all temperatures, means and SD are shown, means indicated by different Latin (for the maternal response) or Greek (for the grand-maternal response) letters are significantly different $(\mathrm{p}<0.05$ with the Tukey HSD test).

mental factors: the multiple correlation coefficients $\mathrm{R}$ varied from 0.883 (T. embryophagum) to 0.985 (T. buesi and $T$. principium). In particular, the direct influence of temperature and the maternal photoperiodic response were the strongest factors, the difference between generations was not as strong, although always highly significant, while the grand-maternal photoperiodic response was significant in 5 of the 6 studied Trichogramma species. In combination, thermal and photoperiodic responses produced a very strong impact: as seen in Figs 1-6 (A-C parts), the difference between treatments (combinations of photoperiodic regimes of development of the grand-maternal and maternal generations and thermal regime of development of the progeny) in most of the studied species reached 80-90\%. In T. telengai (Fig. 6) and in T. embryophagum (Fig. 2) the maximal difference between treatments was smaller because of a strong tendency to diapause which was recorded even under most "diapause-averting" treatments (grand-maternal and maternal females have developed at long day and progeny developed at high temperature).

Interactions of the above factors were also significant with only a few exceptions (Table 3 ). Note that all nonsignificant interactions included grand-maternal photoperiod and in 4 of the 5 cases they were recorded for $T$. embryophagum and T. telengai. From Figs 1-6 (A-C parts) it is seen that in most Trichogramma species developed at most of the temperature regimes used in our study the relative strength of the grand-maternal photoperiodic response markedly depended on the maternal photo-

TABLE 3. Relative strength of the interactions between temperature, grand-maternal photoperiod, maternal photoperiod, and difference between generations in their influence on the proportion of diapausing progeny of Trichogramma species (F-ratios and their significance calculated by 4-way ANOVA of arcsine-transformed data: *** $-\mathrm{p}<0.001,{ }^{* *}-\mathrm{p}<0.01,{ }^{*}-\mathrm{p}<0.05$, n.s. - not significant).

\begin{tabular}{|c|c|c|c|c|c|c|c|c|c|c|c|c|}
\hline \multirow{2}{*}{$\begin{array}{l}\text { Trichogramma } \\
\text { species }\end{array}$} & \multicolumn{2}{|c|}{$\begin{array}{l}\text { Temperature and } \\
\text { grand-maternal } \\
\text { photoperiod }\end{array}$} & \multicolumn{2}{|c|}{$\begin{array}{c}\text { Temperature } \\
\text { and maternal } \\
\text { photoperiod }\end{array}$} & \multicolumn{2}{|c|}{$\begin{array}{l}\text { Temperature } \\
\text { and generation }\end{array}$} & \multicolumn{2}{|c|}{$\begin{array}{l}\text { Maternal photoperiod } \\
\text { and grand-maternal } \\
\text { photoperiod }\end{array}$} & \multicolumn{2}{|c|}{$\begin{array}{c}\text { Generation and } \\
\text { grand-maternal } \\
\text { photoperiod }\end{array}$} & \multicolumn{2}{|c|}{$\begin{array}{c}\text { Generation } \\
\text { and maternal } \\
\text { photoperiod }\end{array}$} \\
\hline & 13.8 & $* * *$ & 36.2 & $* * *$ & 186.9 & $* * *$ & 67.8 & $* * *$ & 26.5 & $* * *$ & 93.9 & $* * *$ \\
\hline T. embryophagum & 1.0 & n.s. & 3.9 & $* * *$ & 47.4 & $* * *$ & 2.3 & $*$ & 1.4 & n.s. & 4.0 & $* * *$ \\
\hline T. evanescens & 8.2 & $* * *$ & 99.0 & $* * *$ & 135.3 & $* * *$ & 1.3 & n.s. & 2.8 & $* *$ & 57.4 & $* * *$ \\
\hline T. piceum & 3.5 & $* *$ & 41.2 & $* * *$ & 120.8 & $* * *$ & 3.0 & $* *$ & 2.0 & $*$ & 23.3 & $* * *$ \\
\hline T. principium & 29.5 & $* * *$ & 207.0 & $* * *$ & 92.3 & $* * *$ & 41.0 & $* * *$ & 14.8 & $* * *$ & 33.8 & $* * *$ \\
\hline T. telengai & 1.1 & n.s. & 68.8 & $* * *$ & 64.4 & $* * *$ & 3.5 & $* * *$ & 1.3 & n.s. & 11.0 & $* * *$ \\
\hline
\end{tabular}



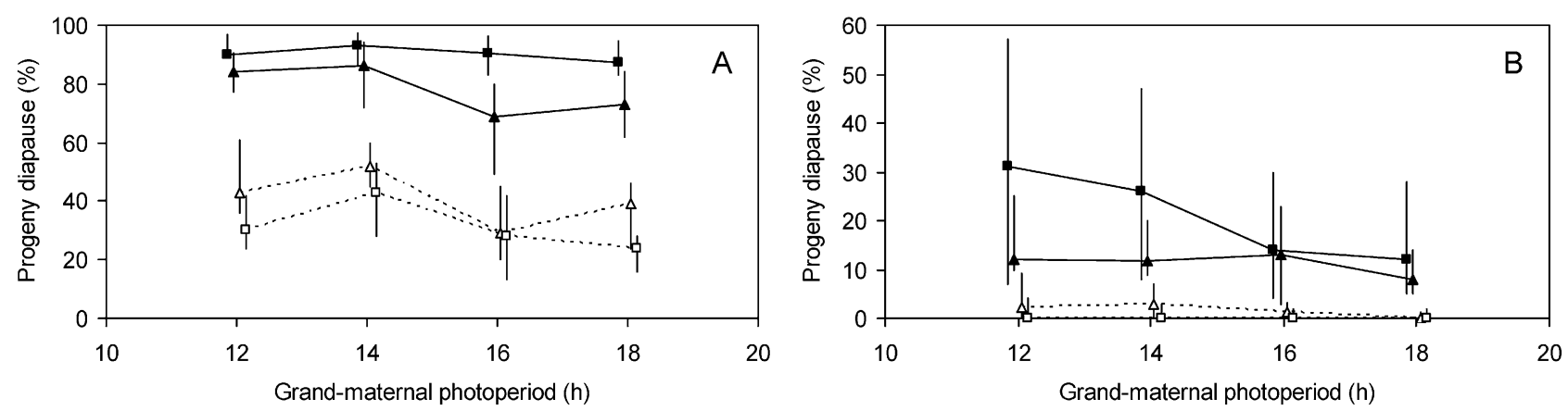

Maternal photoperiod $(\mathrm{h}): \longrightarrow-12 \longrightarrow 14 \cdots \Delta \cdots 16 \cdots \square \cdots 18$

Maternal photoperiod $(\mathrm{h}):-\square 12 \longrightarrow 14 \cdots \Delta \cdots 16 \cdots \cdots \cdots 18$
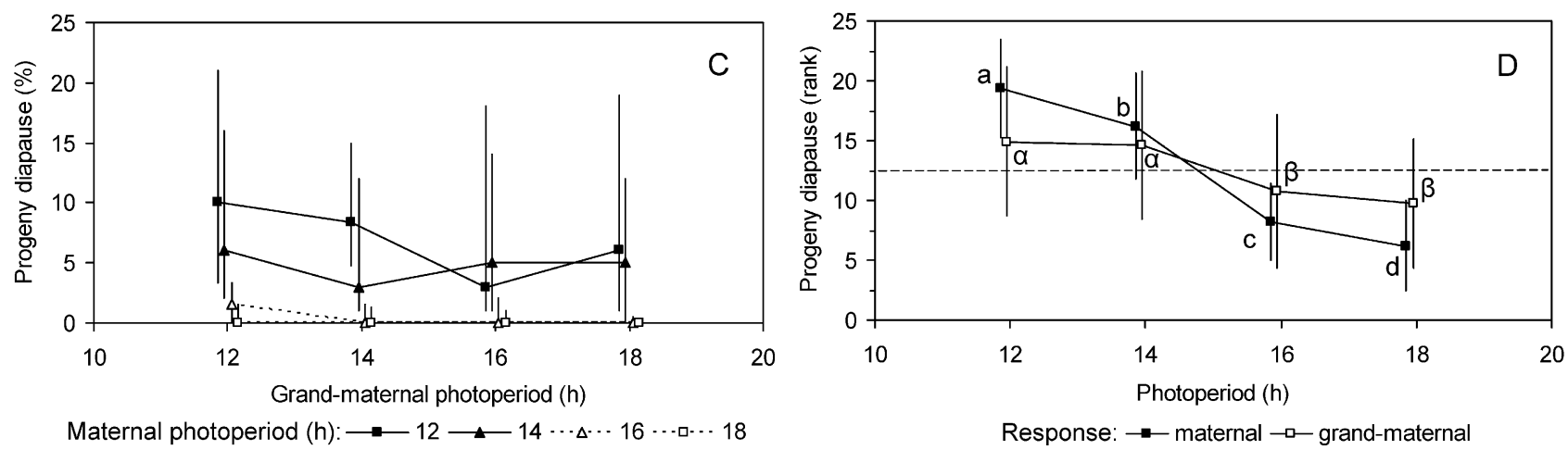

Fig. 3. Maternal and grand-maternal photoperiodic responses of Trichogramma evanescens at different thermal regimes of the progeny development. $\mathrm{A}, \mathrm{B}$, and $\mathrm{C}-$ the progeny developed at 13,14 , and $15^{\circ} \mathrm{C}$, respectively, medians and quartiles are shown. $\mathrm{D}-$ the pooled ranked data for all temperatures, means and SD are shown, means indicated by different Latin (for the maternal response) or Greek (for the grand-maternal response) letters are significantly different $(\mathrm{p}<0.05$ with the Tukey HSD test).

period. To measure this effect, the data for different maternal photoperiods were separately analysed by 3-way ANOVA (grand-maternal photoperiod, temperature, and generation were the factors). As seen in Table 4, with an increase in the maternal photoperiod, the relative strength of the influence of the grand-maternal photoperiod on the proportion of diapausing progeny markedly decreased, while the direct influence of temperature did not show any clear trend. To reveal this general tendency, the $F$-ratios from Table 4 were separately ranked for each Trichogramma species and then the ranks for different species were pooled. The results of this analysis (Fig. 7) suggested that the mean relative strength of the grandmaternal photoperiodic response significantly decreased with the maternal photoperiod, while the strength of the direct thermal response did not show any significant changes.
As was noted above (Table 2, Figs 1-6) the proportion of diapausing progeny was markedly dependent on all of the experimental factors which we have used. Thus, to reveal the species-specific patterns of the maternal and the grand-maternal photoperiodic responses, the data were ranked and plotted against maternal and grandmaternal photoperiods (see Material and Methods for the detailed description of this transformation). Both types of graphs are shown in parts (D) of Figs 1-6. It is clearly seen that the visually estimated thresholds varied from $14.5 \mathrm{~h}$ in T. buesi (Fig. 1) to more than $16 \mathrm{~h}$ in T. embryophagum (Fig. 2), but the thresholds of the maternal and the grand-maternal photoperiodic responses of T. buesi, $T$. embryophagum, and $T$. piceum practically coincided (Figs 1, 2, 4). In T. evanescens (Fig. 3) and T. principium (Fig. 5), the threshold day of the grand-maternal response was slightly longer than that of the maternal response, but

TABLE 4. Relative strength of the influence of grand-maternal photoperiod and temperature on the proportion of diapausing progeny in relation to maternal photoperiod and Trichogramma species (F-ratio and its significance calculated by ANOVA of arcsine-transformed data: $* * *-\mathrm{p}<0.001, * *-\mathrm{p}<0.01, *-\mathrm{p}<0.05$, n.s. - not significant).

\begin{tabular}{|c|c|c|c|c|c|c|c|c|c|c|c|c|}
\hline \multirow{2}{*}{$\begin{array}{l}\text { Maternal photoperiod } \\
\text { Trichogramma } \text { species }\end{array}$} & \multicolumn{2}{|c|}{$12: 12$} & \multicolumn{2}{|c|}{$14: 10$} & \multicolumn{2}{|c|}{$16: 8$} & \multicolumn{2}{|c|}{$18: 6$} & $12: 12$ & $14: 10$ & $16: 8$ & $18: 6$ \\
\hline & & Influ & ence of & rand-1 & laterna & photol & eriod & & \multicolumn{4}{|c|}{ Influence of temperature $(p<0.001$ in all cases $)$} \\
\hline T. buesi & 517.3 & $* * *$ & 212.9 & $* * *$ & 63.7 & $* * *$ & 75.6 & $* * *$ & 126.1 & 356.1 & 159.5 & 142.4 \\
\hline T. embryophagum & 3.3 & $*$ & 3.5 & $*$ & 0.9 & n.s. & 1.7 & n.s. & 192.5 & 136.9 & 152.0 & 159.7 \\
\hline T. evanescens & 11.1 & $* * *$ & 13.7 & $* * *$ & 41.6 & $* * *$ & 10.0 & $* * *$ & 1711.9 & 1965.9 & 2317.4 & 899.2 \\
\hline T. piceum & 8.0 & $* * *$ & 14.9 & $* * *$ & 3.5 & $*$ & 1.4 & n.s. & 725.3 & 939.4 & 721.8 & 723.9 \\
\hline T. principium & 190.9 & $* * *$ & 129.7 & $* * *$ & 38.0 & $* * *$ & 37.0 & $* * *$ & 868.9 & 632.2 & 116.2 & 130.9 \\
\hline T. telengai & 7.2 & $* * *$ & 4.1 & $* *$ & 1.4 & n.s. & 1.2 & n.s. & 142.2 & 326.1 & 441.1 & 858.3 \\
\hline
\end{tabular}



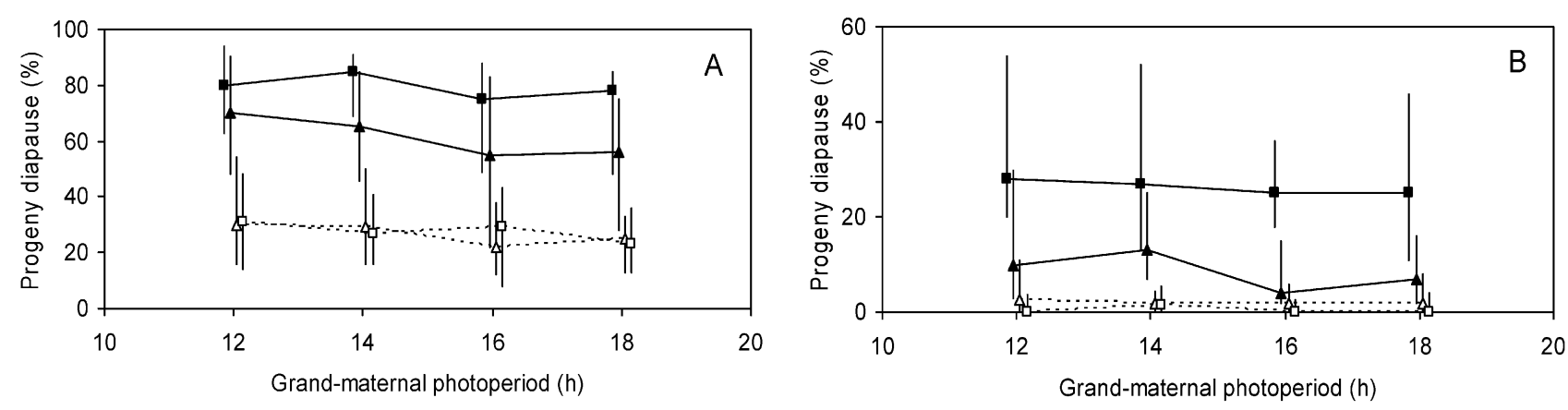

Maternal photoperiod (h): $\longrightarrow-12 \longrightarrow \longleftarrow 14 \cdots \Delta \cdots 16 \cdots \square \cdots 18$
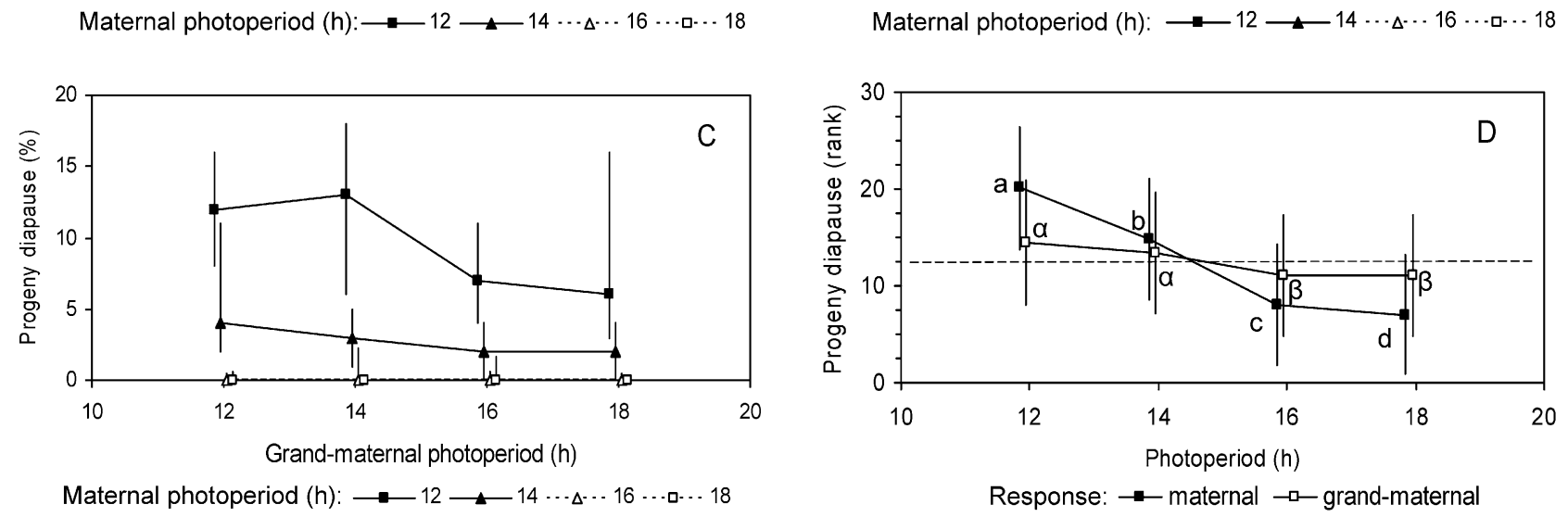

Fig. 4. Maternal and grand-maternal photoperiodic responses of Trichogramma piceum at different thermal regimes of the progeny development. A, B, and $\mathrm{C}-$ the progeny developed at 13,14 , and $15^{\circ} \mathrm{C}$, respectively, medians and quartiles are shown. $\mathrm{D}-$ the pooled ranked data for all temperatures, means and SD are shown, means indicated by different Latin (for the maternal response) or Greek (for the grand-maternal response) letters are significantly different ( $p<0.05$ with the Tukey HSD test).

considering the scale of the graph $(2 \mathrm{~h})$ and the high variability of the results, this small (less than $30 \mathrm{~min}$ ) difference was not significant.

\section{DISCUSSION}

Direct thermal and maternal photoperiodic effects revealed in our experiments have been demonstrated earlier for the studied species as well as for several other representatives of the genus Trichogramma (Bonnemaison, 1972; Zaslavski \& Umarova, 1981, 1990; Mai Phu Qui \& Zaslavski, 1983; Sorokina \& Maslennikova, 1986; Boivin, 1994; Laing \& Corrigan, 1995; Garcia et al., 2002; Reznik et al., 2002; Reznik \& Kats, 2004; Ma \& Chen, 2006; Pizzol \& Pintureau, 2008; Sorokina, 2010; Reznik, 2011), although the diapause-inducing effect of a wide range of photoperiods in combination with a range of thermal regimes has been studied only in $T$. piceum (Reznik et al., 2012b). Similar interaction of direct thermal and maternal photoperiodic responses has been found also in certain other hymenopteran parasitoids from families Aphidiidae (Brodeur \& McNeil, 1989; Polgár \& Hardie, 2000), Braconidae (Ryan, 1965; Kenis, 1997; Li et al., 2008), and Eulophidae (Milonas \& SavopoulouSoultani, 2000).

A significant generational effect that was revealed in our study, also has been demonstrated earlier (Zaslavski \& Umarova, 1981, 1990; Reznik et al., 2002). Similar variations in the tendency to diapause have been observed in the blowfly Calliphora vicina R.-D., which is also a multivoltine insect with a strong maternal effect (Bog- danova et al., 1978; Zaslavski, 1978, 1988; Vinogradova, 1991; Denlinger, 1998). Zaslavski (1988) conceived that this variability is not connected with selection (as suggested, in particular, by the cyclicity of changes) but it is correlated with the maternal effect and may be based on the same mechanism. As for the maternal effect on diapause, its mechanisms may differ in different insects (Mousseau \& Dingle, 1991; Mousseau \& Fox, 1998; Denlinger, 1998, 2002; Saunders et al., 2002; Saunders, 2010). The results of our recent study (Reznik et al., 2012a) suggest that maternal and grandmaternal photoperiodic effects in Trichogramma are probably based on the epigenetic inheritance in the strict sense of the term, i.e. on the transgenerational transmission of variations in DNA expression. On the other hand, the generational effect can be connected with circannual rhythms (Saunders et al., 2002). Note that high intergenerational variability in fecundity, parasitization activity, and other biological parameters has been also reported for Trichogramma females (Reznik et al., 1996; Schmuck et al., 1996; Hoffmann et al., 2001).

As clearly seen from Figs 1-6, the maternal effect on the progeny diapause in all studied species was manifested as a long-day photoperiodic response but the threshold day length varied from ca $14 \mathrm{~h}$ in $T$. principium and $T$. buesi to ca $16 \mathrm{~h}$ in $T$. embryophagum and T. telengai. This difference can be possibly explained by that $T$. embryophagum and T. telengai are widely distributed over Europe and European Russia including Central and North-Western regions, while $T$. principium and $T$. buesi 


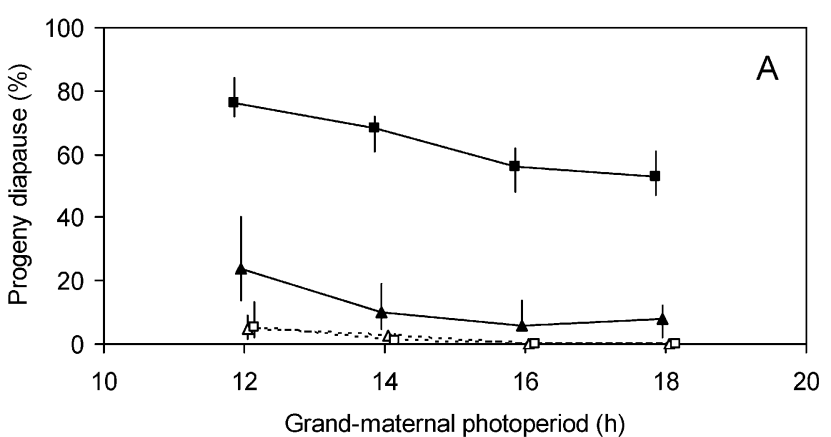

Maternal photoperiod (h): $\longrightarrow-12 \longleftarrow 14 \cdots \Delta \cdots 16 \cdots \square \cdots 18$

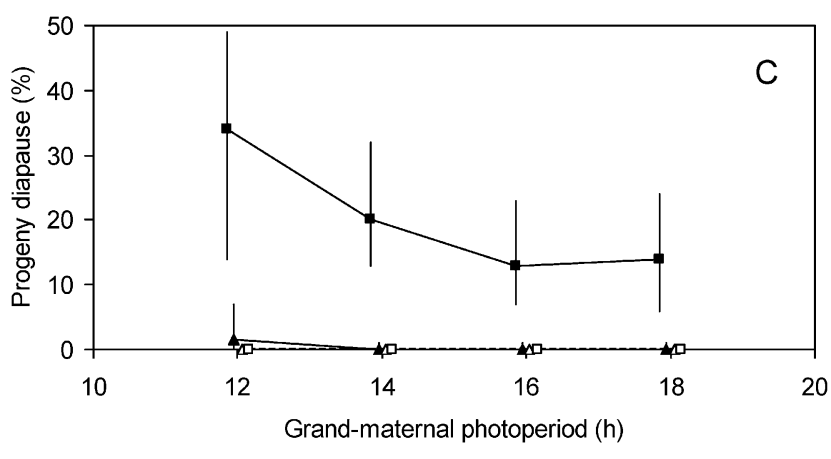

Maternal photoperiod $(\mathrm{h}): \longrightarrow-12 \longrightarrow 14 \cdots \Delta \cdots 16 \cdots \square \cdots 18$

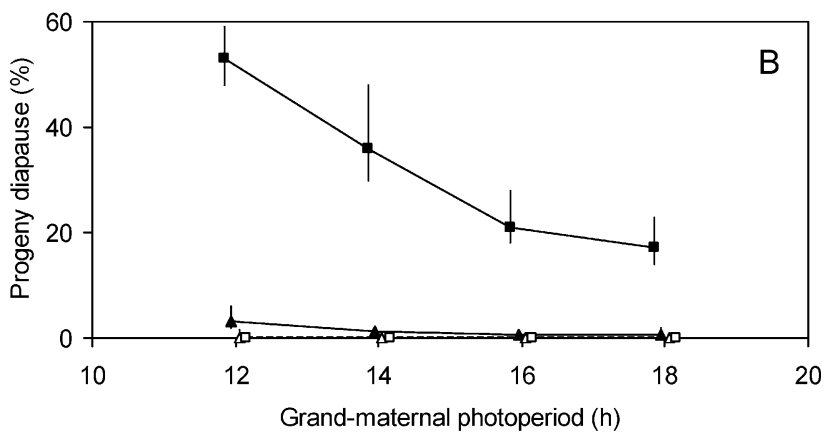

Maternal photoperiod $(\mathrm{h}): \longrightarrow-12 \longrightarrow 14 \cdots \Delta \cdots 16 \cdots \square \cdots 18$

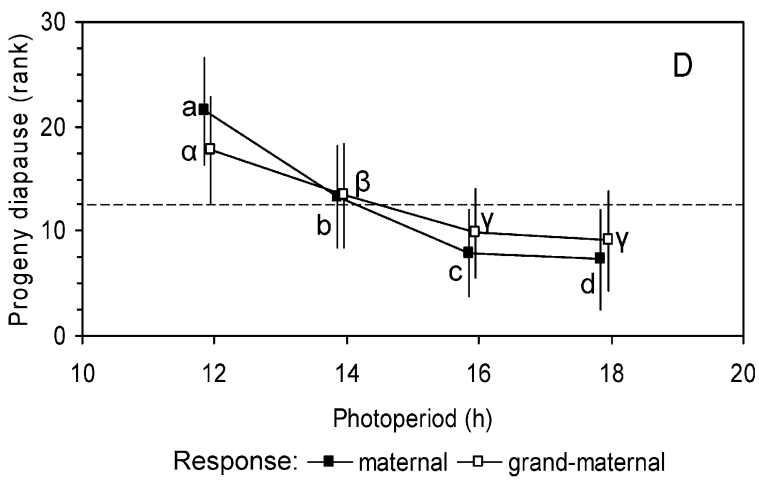

Fig. 5. Maternal and grand-maternal photoperiodic responses of Trichogramma principium at different thermal regimes of the progeny development. A, B, and $\mathrm{C}-$ the progeny developed at 13,14 , and $15^{\circ} \mathrm{C}$, respectively, medians and quartiles are shown. $\mathrm{D}-$ the pooled ranked data for all temperatures, means and SD are shown, means indicated by different Latin (for the maternal response) or Greek (for the grand-maternal response) letters are significantly different ( $\mathrm{p}<0.05$ with the Tukey HSD test).

occur only in Southern Europe, Southern Russia, Southern Kazakhstan, and Central Asia (Table 1), where the optimal time to enter diapause coincides with much shorter days. This latitudinal variation in threshold of photoperiodic response has been found in many insect taxa (Tauber et al., 1986; Zaslavski, 1988; Saunders et al., 2002, Danks, 2007; Saunders, 2010).

Analyzing the results of this study it should be remembered that not photoperiod but temperature is the main diapause-inducing factor in Trichogramma species. Moreover, in some Trichogramma species inhabiting northern Europe (St. Petersburg province) the maternal photoperiodic response was not detected and diapause seemed to be regulated only by temperature signals (Sorokina, 2010). The threshold of the direct thermal response exhibits wide intraspecific variation, but usually temperatures of $10-12^{\circ} \mathrm{C}$ are optimal for diapause induction, temperatures of $17-20^{\circ} \mathrm{C}$ and higher stimulate active development independently of day length, while temperatures of $8^{\circ} \mathrm{C}$ and lower lead to cold quiescence rather than to diapause. The maternal photoperiodic response of Trichogramma species can be usually revealed at temperatures of $13-15^{\circ} \mathrm{C}$ (Zaslavski \& Umarova, 1981, Mai Phu Qui \& Zaslavski, 1983; Sorokina \& Maslennikova, 1986; Zaslavski \& Umarova, 1990; Boivin, 1994; Laing \& Corrigan, 1995; Garcia et al., 2002; Reznik et al., 2002; Reznik \& Kats, 2004; Ma \& Chen, 2006; Pizzol \& Pintureau, 2008; Sorokina, 2010; Reznik, 2011; Reznik et al., 2011a, b, 2012a, b). This photoperiodically based maternal modification of the thermal response avoids the untimely induction of diapause in response to occasional cold waves in spring - early summer, when the temperatures of $13-15^{\circ} \mathrm{C}$ are combined with much longer days than in autumn. Thus, under natural conditions, the induction of diapause is synchronized both with the astronomical season (the photoperiodic response) and with the peculiarity of a given year (the thermal response).

The grand-maternal effect was statistically significant in 2 of the 3 newly investigated species. In combination with the earlier published data (Zaslavski \& Umarova, 1981; Mai Phu Qui \& Zaslavski, 1983; Reznik \& Kats, 2004) this result suggests that the influence of the grandmaternal photoperiod on the diapause incidence in their grand-progeny is rather a rule than an exception in Trichogramma wasps, although the relative importance of this response may vary greatly from species to species. It is noteworthy that the grand-maternal effect was the strongest in T. buesi and T. principium (which, as was noted above, inhabit only the south of Palearctic) and the weakest in T. embryophagum and T. telengae whose geographical ranges extend relatively far to the north. Possibly this tendency may be explained by that in the northern temperate zone Trichogramma wasps develop slowly and enter diapause early, and thus the grandmothers of the diapausing generation develop under long day conditions, but the number of the studied species is not yet sufficient for a certain conclusion. 


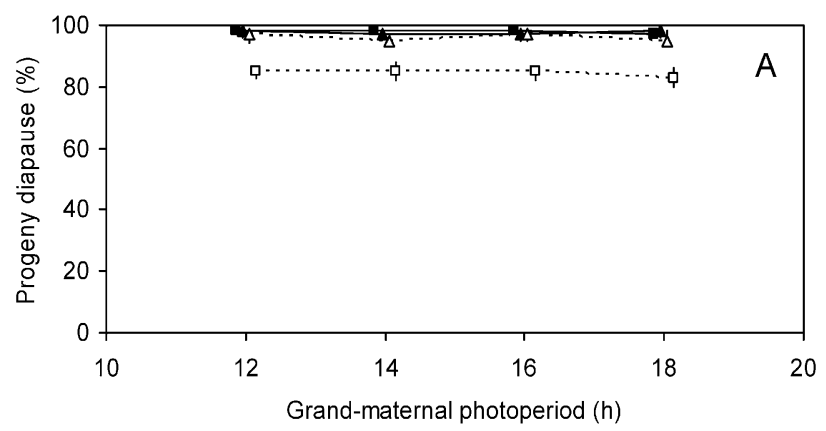

Maternal photoperiod (h): $\square-12 \longrightarrow 14 \cdots \Delta^{\cdots} \cdot 16 \cdots-\cdots 18$

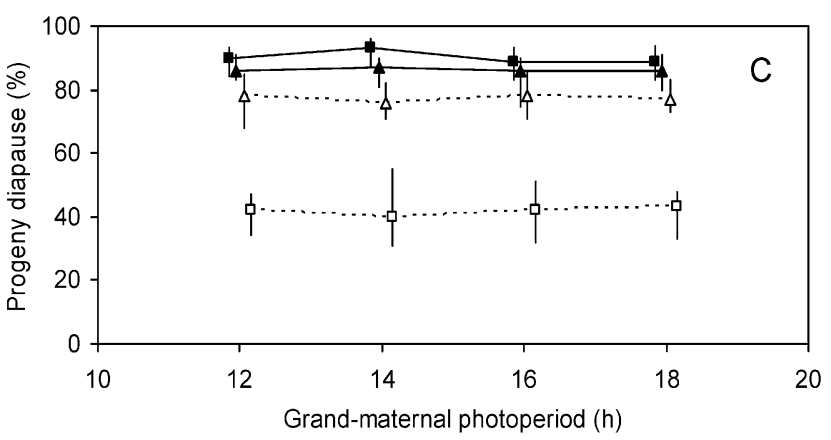

Maternal photoperiod $(\mathrm{h}): \longrightarrow-12 \longrightarrow 14 \cdots \Delta \cdots 16 \cdots \cdots \cdot 18$

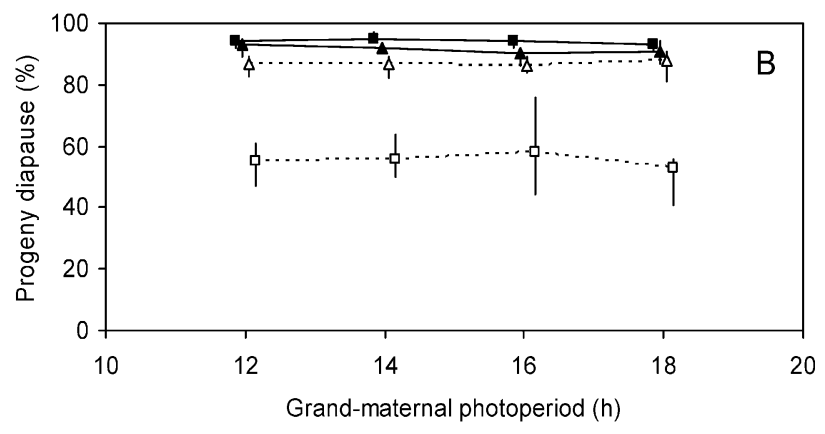

Maternal photoperiod $(\mathrm{h}): \longrightarrow-12 \longrightarrow 14 \cdots \Delta \cdots 16 \cdots \square \cdots 18$

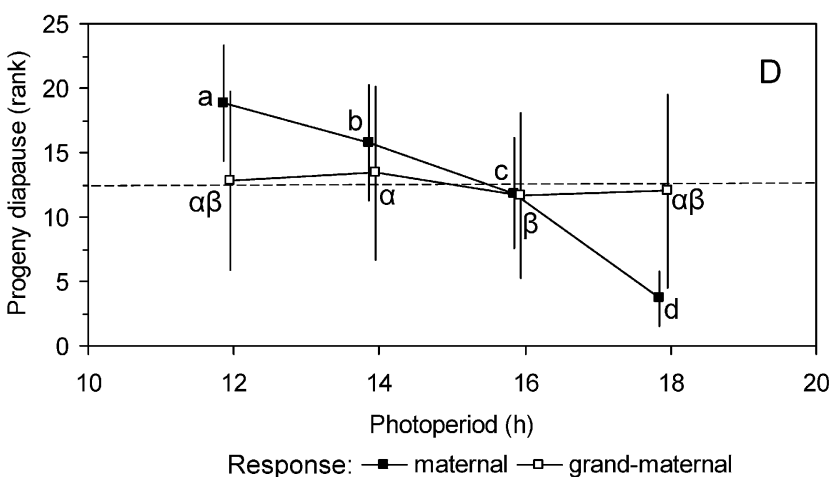

Fig. 6. Maternal and grand-maternal photoperiodic responses of Trichogramma telengai at different thermal regimes of the progeny development. A, B, and $\mathrm{C}$ - the progeny developed at 13,14 , and $15^{\circ} \mathrm{C}$, respectively, medians and quartiles are shown. $\mathrm{D}-$ the pooled ranked data for all temperatures, means and SD are shown, means indicated by different Latin (for the maternal response) or Greek (for the grand-maternal response) letters are significantly different ( $p<0.05$ with the Tukey HSD test).

The so called "stepwise photoperiodic reaction" or the response to the direction of change in the length of the day has been observed in several insect species (Tauber et al., 1986; Zaslavski, 1988; Saunders et al., 2002). Indeed, a slight but statistically significant effect of the change in photoperiod was demonstrated for $T$. principium (Reznik $\&$ Kats, 2004). However, in the present study, this effect was not recorded: when grand-mothers developed at longer day than mothers did, the proportion of diapausing progeny was not higher than when both mothers and grand-mothers developed at the shorter of the two photoperiods. This contradiction, however, can be explained by that in the present study we used "natural" day lengths from 12 to $18 \mathrm{~h}$, while the stepwise photoperiodic reaction in T. principium was detected only under ultra-short photoperiods (Reznik \& Kats, 2004). Note that in these experiments photoperiod differed between generations but was always constant during development of a given generation. In the other studies on the insect response to the changing day length, the changes occurred within one generation (Tauber et al., 1986; Zaslavski, 1988; Saunders et al., 2002). Experiments of this kind have been also conducted with Trichogramma wasps, the stepwise photoperiodic response was very weak (Ivanov \& Reznik, 2008) or was not significant (Reznik et al., 2011b).

Returning to the main aim of our study, we conclude that the first hypothesis was not supported by the experimental data: the thresholds of the maternal and the grandmaternal photoperiodic responses of the studied species coincided or almost coincided. It may be speculated that experiments with finer scale of day length could demonstrate small differences between maternal and grandmaternal thresholds. However, considering that the prepupal diapause in Trichogramma wasps can be induced only at temperatures of $14-15^{\circ} \mathrm{C}$ or lower, the development of the preceding (maternal) generation in the natural conditions lasts about a month. At the latitudes of $40-50^{\circ}$ (where the species with the strong grand-maternal effect occur) in the end of summer-autumn the decrease in the daylength during one month is $1-2 \mathrm{~h}$. Thus, the corresponding ecologically significant difference between thresholds of photoperiodic responses, if it exists, would have been detected in our experiments. Hence, we conclude that a difference between the thresholds of the maternal and the grand-maternal photoperiodic responses of the studied Trichogramma species is absent or at least it has little or no ecological value.

Our second hypothesis, on the contrary, was confirmed by the experiments. The relative effect of the grandmaternal photoperiod on the proportion of diapausing progeny markedly decreased with increasing maternal photoperiod (Table 4, Fig. 7). Note that this trend cannot be explained (or can be only partly explained) by the strong diapause-averting effect of the long maternal photoperiod which inhibits the induction of diapause and thus suppresses the manifestation of any other photo-thermal response. First, the relative strength of the direct thermal response was not significantly dependent on the photope- 


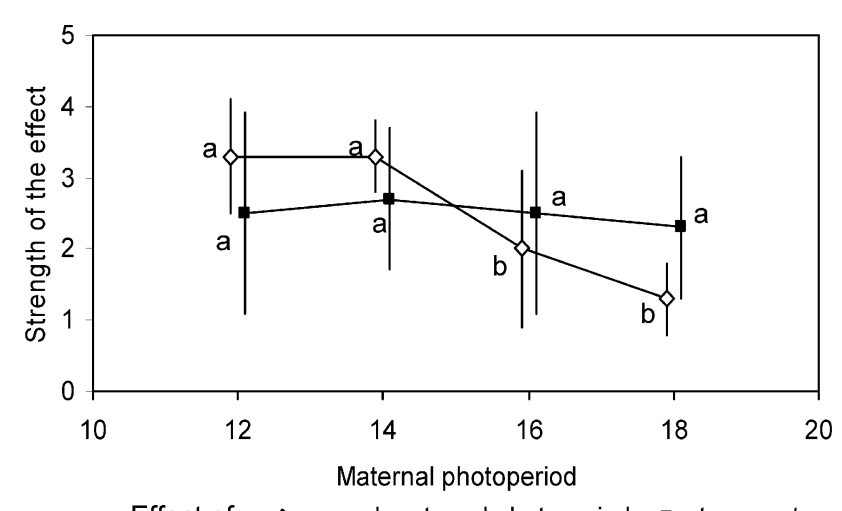

Effect of: $\diamond$ grand-maternal photoperiod $\rightarrow$-temperature

Fig. 7. Influence of photoperiodic conditions of development of the maternal generation on the relative strength of the grandmaternal photoperiodic response and of the direct thermal response. Means and SD of ranked F-ratios (see Table 4) are shown. Means indicated by different letters along the same line are significantly different $(\mathrm{p}<0.05$ with the Tukey HSD test).

riodic conditions of development of the maternal females. Second, the decrease in the strength of the grand-maternal effect was observed not only when the long maternal photoperiod reduced the proportion of diapausing progeny to less than 10-20\% (Figs 1, 4, and 5) but also when the percentage of diapausing individuals moved towards $50 \%$ (Figs 2 and 6). Theoretically it could be expected that the "threshold zone" of the maternal photoperiodic response is most sensitive to the "grand-maternal correction". This assumption is suggested, for example, by the analogy with the maternal photoperiodic correction of the direct thermal response which in Trichogramma species can be detected only at near-threshold temperatures (Zaslavski \& Umarova, 1981, 1990; Boivin, 1994; Reznik, 2011). Similarly, the thermal correction of the photoperiodic response is often strongly manifested near the photoperiodic threshold (Tauber et al., 1986; Zaslavski, 1988; Saunders et al., 2002). Generally, the maximum sensitivity zone (the maximum derivative) of a sigmoidal "dose-response" curve also occurs at the 50\% level.

As was noted in the Introduction, only a few studies have been devoted to ecological or physiological aspects of the grand-maternal photoperiodic effect in insects. In particular, endogenous circannual rhythms which have been found in several insect species from different taxa are undoubtedly based on the transgenerational transfer of information. These rhythms can be entrained by seasonal changes in day length but this phenomenon differs essentially from the grand-maternal photoperiodic response (Zaslavski, 1988; Saunders et al., 2002; Danks, 2007; Saunders, 2010). The "interval timer" that extends over several generations and inhibits the diapause-inducing effect of short day conditions in the aphid Megoura viciae Buckton (Lees, 1960; Saunders et al., 2002, Saunders, 2010) is somewhat similar to the transgenerational photoperiodic response. However, this reaction is triggered by photoperiod not directly but via the diapause induction (response to short days is blocked in the progeny of aphids which emerged from overwintered eggs). Larval diapause in the blowfly Calliphora vicina R.-D., a very popular insect model for various experimental studies, was shown to be regulated by interaction of direct and maternal responses to the thermal and photoperiodic conditions of the environment (Vinogradova, 1991; Denlinger, 1998, 2002; Saunders et al., 2002; Saunders, 2010) and these reactions seem to be very similar to those described for Trichogramma species (Reznik, 2011). Particularly, multigenerational laboratory experiments suggested that direct and maternal photoperiodic responses of C. vicina are based on one and the same physiological mechanism (Bogdanova et al., 1978). Based on the results of that study, Zaslavski (1978) also reasoned that in the natural conditions the adaptation to the seasonal changes of the climate results from the interaction of photothermal responses of the sequence of generations.

Summarizing the results of our study we conclude that the grand-maternal and the maternal effects on Trichogramma progeny diapause are most probably based on one and the same photoperiodic response and from this aspect the grand-maternal effect can be considered as a simple continuation of the maternal effect to the next and the following (Reznik et al., 2012a) - generations. However, the relative strength of this transgenerational impact varies markedly among Trichogramma species and depends significantly on the photoperiodic conditions of development of the maternal generation. The grandmaternal effect might conceivably increase the proportion of diapausing individuals in the late autumn, in the progeny of females which have developed under short day conditions during two and more generations, thus achieving a "cumulative" photoperiodic response.

ACKNOWLEDGEMENTS. We thank T.Ya. Umarova for the excellent technical assistance. We are deeply thankful to the two anonymous reviewers for valuable critical comments and suggestions. This work was partly supported by the Programme "Biological Resources of Russia: dynamics under global climatic and anthropogenic change" of the Department of Biological Sciences, Russian Academy of Sciences.

\section{REFERENCES}

Borvin G. 1994: Overwintering strategies of egg parasitoids. In Wajnberg E. \& Hassan S.A. (eds): Biological Control with Egg Parasitoids. CAB International, Wallingford, pp. 219-244.

Bogdanova T.P., Vinogradova E.B. \& Zaslavski V.A. 1978: Interrelations between the reactions controlling diapause and maternal influence in Calliphora vicina R.-D. - Trudy Zool. Inst. Akad. Nauk SSSR (Leningrad) 69: 62-79 [in Russian].

Bonnemaison L. 1972: Diapause et superparasitisme chez Trichogramma evanescens Westw. (Hymenoptera, Trichogrammatidae). - Bull. Soc. Entomol. Fr. 77: 122-132.

Brodeur J. \& McNeil J.N. 1989: Biotic and abiotic factors involved in diapause induction of the parasitoid, Aphidius nigripes (Hymenoptera: Aphidiidae). - J. Insect Physiol. 35: 969-974.

DANKS H.V. 2007: The elements of seasonal adaptations in insects. - Can. Entomol. 139: 1-44.

DenLINGER D.L. 1998: Maternal control of fly diapause. In Mousseau T.A. \& Fox C.W. (eds): Maternal Effects as Adaptations. Oxford University Press, New York, pp. 275-287. 
Denlinger D.L. 2002: Regulation of diapause. - Annu. Rev. Entomol. 47: 93-122.

Garcia P.V., Wajnberg E., Pizzol J. \& OlivejRa M.L.M. 2002: Diapause in the egg parasitoid Trichogramma cordubensis: role of temperature. - J. Insect Physiol. 48: 349-355.

HofFMAnN M.P., Ode P.R., WALker D.L., Gardner J., VAN Nounuys S. \& Shelton A.M. 2001: Performance of Trichogramma ostriniae (Hymenoptera: Trichogrammatidae) reared on factitious hosts, including the target host, Ostrinia nubilalis (Lepidoptera: Crambidae). - Biol. Contr. 21: 1-10.

Ivanov M.F. \& ReZnIK S.YA. 2008: Photoperiodic regulation of the diapause of the progeny in Trichogramma embryophagum Htg. (Hymenoptera, Trichogrammatidae): dynamics of sensitivity to photoperiod at the immature stages of maternal females. - Entomol. Rev. 88: 261-268.

KenIS M. 1997: Biology of Coeloides sordidator (Hymenoptera: Braconidae), a possible candidate for introduction against $P i s-$ sodes strobi (Coleoptera: Curculionidae) in North America. - Biocontr. Sci. Techn. 7: 153-164.

LAING J.E. \& CORRIGAN J.E. 1995: Diapause induction and postdiapause emergence in Trichogramma minutum Riley (Hymenoptera: Trichogrammatidae): the role of host species, temperature, and photoperiod. - Can. Entomol. 127: $103-110$.

LeEs A.D. 1960: The role of photoperiod and temperature in the determination of parthenogenetic and sexual forms in the aphid Megoura viciae Buckton. II. The operation of the "interval timer" in young clones. - J. Insect Physiol. 4: $154-175$.

Li W.-X., Li J.-C., Coudron T.A., Lu Z.-Y., Pan W.-L., Liu X.-X. \& Zhang Q.-W. 2008: Role of photoperiod and temperature in diapause induction of endoparasitoid wasp Microplitis mediator (Hymenoptera: Braconidae). - Ann. Entomol. Soc. Am. 101: 613-618.

MA C.-S. \& CHEN Y.-W. 2006: Effects of constant temperature, exposure period, and age on diapause induction in Trichogramma dendrolimi. - Biol. Contr. 36: 267-273.

Mai Phu Qui \& Zaslavski V.A. 1983: Photoperiodic and thermal responses of Trichogramma euproctidis (Hymenoptera, Trichogrammatidae). - Zool. Zh. 62: 1676-1680 [in Russian].

Milonas P.G. \& Savopoulou-Soultani M. 2000: Diapause induction and termination in the parasitoid Colpoclypeus florus (Hymenoptera: Eulophidae): role of photoperiod and temperature. - Ann. Entomol. Soc. Am. 93: 512-518.

Mousseau T.A. \& Dingle H. 1991: Maternal effects in insect life histories. - Annu. Rev. Entomol. 36: 511-534.

Mousseau T.A. \& Fox C.W. 1998: The adaptive significance of maternal effects. - Trends Ecol. Evol. 13: 403-407.

Pizzol J. \& Pintureau B. 2008: Effect of photoperiod experienced by parents on diapause induction in Trichogramma cacoeciae. - Entomol. Exp. Appl. 127: 72-77.

PolgÁr L.A. \& Hardie J. 2000: Diapause induction in aphid parasitoids. - Entomol. Exp. Appl. 97: 21-27.

REZNIK S.YA. 2011: Ecological and evolutionary aspects of photo-thermal regulation of diapause in Trichogramma. $-J$. Evol. Biochem. Physiol. 47: 512-523.

ReZnIK S.YA. \& Kats T.S. 2004: Exogenous and endogenous factors inducing diapause in Trichogramma principium Sug. et Sor. (Hymenoptera, Trichogrammatidae). - Entomol. Rev. 84: 963-970.

Reznik S.Ya., VoInovich N.D. \& Umarova T.Ya. 1996: Experimental studies of the dynamics of the percentage of ovipositing females and their fecundity in the generation sequence of Trichogramma (Hymenoptera, Trichogrammatidae). Entomol. Rev. 76: 138-143.
Reznik S.Ya., Kats T.S., Umarova T.Ya. \& Voinovich N.D. 2002: Maternal age and endogenous variation in maternal influence on photoperiodic response in the progeny diapause in Trichogramma embryophagum (Hymenoptera, Trichogrammatidae). — Eur. J. Entomol. 99: 175-181.

REZNIK S.YA., VoINOVICH N.D. \& VAGHina N.P. 2011 a: Maternal regulation of Trichogramma embryophagum Htg. (Hymenoptera: Trichogrammatidae) diapause: Photoperiodic sensitivity of adult females. - Biol. Contr. 57: 158-162.

Reznik S.YA., Vaghina N.P. \& Voinovich N.D. 2011b: Maternal influence on diapause induction in Trichogramma (Hymenoptera, Trichogrammatidae): the dynamics of photosensitivity. - J. Appl. Entomol. 135: 438-445.

Reznik S.Ya., Vaghina N.P. \& Voinovich N.D. 2012a: Multigenerational maternal effect on diapause induction in Trichogramma species (Hymenoptera: Trichogrammatidae). Biocontr. Sci. Techn. 22: 429-445.

Reznik S.YA., Vaghina N.P. \& Vasiljev A.L. 2012b: Photothermal regulation of diapause in Trichogramma piceum Djur. (Hymenoptera, Trichogrammatidae). - Entomol. Rev. 91: 485-491.

RYAN R.B. 1965: Maternal influence on diapause in a parasitic insect Coeloides brunneri Vier. (Hymenoptera: Braconidae). - J. Insect Physiol. 11: 1331-1336.

SAUNDERS D.S. 2010: Photoperiodism in insects: Migration and diapause responses. In Nelson R.J., Denlinger D.L. \& Somers D.E. (eds): Photoperiodism: The Biological Calendar. Oxford University Press, New York, pp. 218-257.

Saunders D.S., Steel C.G.H., Vafopoulou X. \& Lewis R.D. 2002: Insect Clocks. Elsevier, Amsterdam, 576 pp.

Schmuck R., Mager H., KüNast C.H., Bock K.-D. \& StrockWEYHERMÜLLER S. 1996: Variability in the reproductive performance of beneficial insects in standard laboratory toxicity assays - implications for hazard classification of pesticides. - Ann. Appl. Biol. 128: 437-451.

Sмiтн S.M. 1996: Biological control with Trichogramma: advances, successes, and potential of their use. - Annu. Rev. Entomol. 41: 375-406.

SoROKINA A.P. 2001: Evaluation of Trichogramma Species Promising for Plant Protection. All-Russian Institute of Plant Protection, St. Petersburg, 44 pp. [in Russian].

Sorokina A.P. 2010: Photo-thermal reactions controlling diapause in three Trichogramma species from Leningrad province. - Vest. Zash. Rast. 3: 51-54 [in Russian].

Sorokina A.P. \& MAsLENNIKova V.A. 1986: The peculiarities of photo-thermal reactions in certain species of the genus Trichogramma (Hymenoptera, Trichogrammatidae). - Vest. Leningrad. Gos. Univ. (Ser. 3) 1: 9-14 [in Russian].

Tauber M.J., Tauber C.A. \& Masaki S. 1986: Seasonal Adaptations of Insects. Oxford University Press, New York, Oxford, $411 \mathrm{pp}$.

VINOGRADOVA E.B. 1991: Diapause of flies and its regulation. Trudy Zool. Inst. Akad. Nauk SSSR (Leningrad) 214: 1-255 [in Russian].

ZASLAVSKI V.A. 1978: Inductive and spontaneous processes in insect photoperiodism. - Trudy Zool. Inst. Akad. Nauk SSSR (Leningrad) 69: 5-61 [in Russian].

Zaslavski V.A. 1988: Insect Development: Photoperiodic and Temperature Control. Springer, New York, Berlin, 187 pp.

Zaslavski V.A. \& Umarova T.Ya. 1981: Photoperiodic and temperature control of diapause in Trichogramma evanescens Westw. (Hymenoptera, Trichogrammatidae). - Entomol. Obozr. 60: 721-731 [in Russian].

ZASLAVSKI V.A. \& UMAROVA T.YA. 1990: Environmental and endogenous control of diapause in Trichogramma species. Entomophaga 35: 23-29.

Received October 24, 2012; revised and accepted January 24, 2013 